\title{
Prediction of Hope Based on Spirituality Components with Healthy Intermediaries in Students
}

\author{
Farideh mohammadi ${ }^{1} \quad$ Nasrin Hojjatzadeh $^{2}$ \\ 1.Masters degree,Psychologyof Exeeptional childrens Trend, Azad university, Birjand university,mashhad,iran \\ 2.Student P.H.D,Psychologyof Exeeptional childrens trends, Azad university, Birjand university,birjand,iran
}

\begin{abstract}
The purpose of this study was to provide a model based on the relationship between hope and spirituality based on general health mediation. Other research has mainly considered general health as a dependent variable. However, the present study seeks to evaluate general health as a mediator variable. This will promote theoretical literature in this area. The statistical population of the studying students was Allameh Tabatabaei University, from which 300 samples were selected by cluster sampling. Instruments included: Spirituality Questionnaire, Life Expectancy Questionnaire, and General Health Questionnaire (GHQ). The research was a correlational study in which the hope of dependent variable, independent spirituality, general health, mediating variable and data were analyzed by path analysis. The results showed that spirituality and general health are a predictor of hope, and general health has a mediator role for prediction of hopefulness. General health was also predicted by spirituality. Keywords: Spirituality, Hope and General Health.
\end{abstract}

DOI: $10.7176 /$ RHSS/9-12-11

Publication date:June $30^{\text {th }} 2019$

\section{Introduction}

By the end of the 1970s, optimism and hope were a general disorder and a sign of impoliteness or weakness, while a balanced and unbiased assessment of the person's future expectations was a sign of general health, sophistication and vigor (Petersen, 2000). Hope includes the ability to design strategies to target goals, in contrast to the barriers, and the agency or motive for using these strategies. Hope is growing in a clear and defined way during infancy, childhood, and adolescence (Schneider, 2000). Children whose promising nature is raised often have parents who act as promising role models and guide their children in designing and implementing plans to tackle barriers to valued ideals. These children have a secure attachment to their parents, providing them with a warm environment with a family structure. In this type of environment, the rules are applied in a sustainable and predictable manner, and the conflict is managed fairly and predictably (Schneider, 2000).

Since the time of Sigmund Freud, therapists have kept themselves away from spiritual and religious issues because of their fear of disturbing clients and obscuring professional boundaries. However, recent developments in related theories and research have shown that the spiritual and religious beliefs of clients who visit psychiatric centers play an important role in the process of coping with a variety of problems. On the other hand, the status of general health in relation to these concepts is to be considered seriously (Free, 2005).

The present study seeks to provide a model for the relationship between hope and spirituality, based on general health mediation. Other research has mainly considered general health as a dependent variable. While this study seeks to assess general health as a mediator variable. This will promote theoretical literature in this field. Based on this, the following goals are pursued in the present research.

1. Investigating the predictive role of spirituality on hope

2. Investigating the predictive role of spirituality on general health

3. Investigating the predictive role of general health on hope

4. Investigating the mediating role of general health among the components of spirituality and hope

\section{Research Methodology}

This research is a correlation type in which the hope of dependent variable, spirituality is independent variable and general health is mediator or mediator variable.

\subsection{Statistical population, sampling method and sample size}

Statistical population: Students working at Allameh Tabatabaei University were selected by cluster sampling from different colleges of about 10 classes and a total of 300 students.

Table (1-3): Number and distribution of statistical sample of research

\begin{tabular}{|c|c|c|c|c|c|c|}
\hline & $\begin{array}{c}\text { Faculty of } \\
\text { economy }\end{array}$ & $\begin{array}{c}\text { Faculty of } \\
\text { psychology }\end{array}$ & $\begin{array}{c}\text { Faculty of } \\
\text { management }\end{array}$ & $\begin{array}{c}\text { Faculty of } \\
\text { sociology }\end{array}$ & $\begin{array}{c}\text { Faculty of } \\
\text { literature }\end{array}$ & total \\
\hline Females & 25 & 45 & 32 & 29 & 42 & 173 \\
\hline Males & 29 & 32 & 24 & 23 & 19 & 127 \\
\hline total & 54 & 77 & 56 & 52 & 61 & 300 \\
\hline
\end{tabular}


A sample of 300 students was selected from five faculties of Allameh Tabatabaei University in Tehran. From each faculty, according to the number of students, the subjects were selected as shown in the table below.

\section{3-3 Research Tools}

\section{3-3-1 Spirituality Questionnaire}

This questionnaire was designed by Hall and Edwards (1996) to assess the two dimensions of the growth of spirituality, namely, the awareness of the Supreme Being and the quality of relationship with God. The initial version of the test had 5 subscales of awareness, real acceptance, hopelessness, magnification, and instability. In 2002, Hall and Edwards re-evaluated the scale and added a sub-management of withdrawal. So the current version has 6 subsamples. Spirituality Questionnaire is a self-report tool with 47 questions, some of which are composed of two parts. The subject must express his acceptance or opposition to each of the phrases on a Likert scale of 5 degrees. Cronbach's alpha is a subset of awareness, acceptance, disappointment, magnification, and instability and impression management respectively of $0.95,0.83,0.90,0.73,0.84$ and 0.77 , respectively. For scoring, scores of each scale are summed altogether and the questionnaire does not reverse the score.

In this research, the reliability of the components of spirituality questionnaire was calculated by Cronbach's alpha method (Table 2-3).

Table (2-3) Cronbach's Alpha Components of Spirituality

\begin{tabular}{|c|c|c|}
\hline scale & No. of questions & Cronbach Alpha \\
\hline Awareness & 19 & 0.80 \\
\hline Reception & 7 & 0.83 \\
\hline Disappointment & 7 & 0.84 \\
\hline Magnification & 7 & 0.70 \\
\hline Instability & 9 & 0.71 \\
\hline impression management & 5 & 0.56 \\
\hline
\end{tabular}

\section{3-3-2 Life expectancy questionnaire}

This questionnaire was developed by Schneider (2002) to measure hopes, which has 12 questions and is selfassessing. Four questions for measuring factor thinking, four questions for measuring strategic thinking, and four divergent questions. Therefore, the questionnaire includes two factor and strategy scales.

A great deal of research has shown the reliability and desirability of this tool. The internal consistency of the whole test is from $0 / 74$ to 0.84 , and the test-retest reliability is $80 / 8$ and over the period from 8 to 10 weeks is higher than this (Schneider and Lopez, 2007). The internal consistency of the factor subscale is 0.71 to 0.76 and the strategic subscale is 0.63 to 0.80 (Schneider and Lopez, 2002).

How to score: In the test score, 4 questions are added. 4 questions for factor hope and 4 questions for strategic hope are summed up altogether and the sum of these two subscales represents the overall score of hope.

In this research, the reliability of life expectancy inventory components was calculated using Cronbach's alpha (Table 3-3)

Table 3-3 Cronbach's Alpha Hope Questionnaire

\begin{tabular}{|c|c|c|}
\hline scale & No. of questions & Cronbach Alpha \\
\hline Agent hope & 4 & 0.73 \\
\hline Strategic hope & 4 & 0.71 \\
\hline Whole test & 12 & 0.79 \\
\hline
\end{tabular}

\subsubsection{General Health Questionnaire (GHQ)}

The questionnaire has 28 questions, which measures four subscales of physical symptoms, anxiety and insomnia, social function, and depression. In Goldberg and Williams (1998), the validity of dual-test for the whole questionnaire was 0.95. In Iran, Yaghubi (1995) has Cronbach alpha of 0.85, 0.78, 0.79 and 0.91 for subscales of physical symptoms, anxiety and insomnia, social function, and depression.

Also, Poverty in Iran has reported the reliability of the questionnaire by three methods of re-evaluation, dualization, and Cronbach's alpha, respectively: 0.70, 0.90, and 0.93 respectively. Also, this researcher used the validity of the questionnaire to examine the three methods of simultaneous validity, the correlation of the subquests of this questionnaire with the total score and factor analysis. The simultaneous implementation of the questionnaire by Middlesex results obtained a correlation coefficient of 0.55 . The correlation coefficients between the subtest tests of this questionnaire and the total score were satisfactory and ranged from 0.72 to 0.87 . To score 7 primary questions for the physical aspect, 8 to 14 for anxiety, 15 to 21 for social and 22 to 28 for depression. A total of 4 sub-scales represent the overall health score.

In this research, the reliability of the components of the general health questionnaire was calculated by Cronbach's alpha method (Table 3-4). 
Table 3-4. Cronbach's Alpha General Health Questionnaire

\begin{tabular}{|c|c|c|}
\hline scale & No. of questions & Cronbach alpha \\
\hline Physical & 7 & 0.69 \\
\hline Anxiety & 7 & 0.74 \\
\hline Social & 7 & 0.70 \\
\hline Depression & 7 & 0.83 \\
\hline Whole test & 28 & 0.89 \\
\hline
\end{tabular}

\section{4. Analysis of information}

To test the hypothesis and analyze the data, the path analysis method was used by Baron and Kenny (1986) method. During this statistical model, the predictive role of spirituality for hope and spirituality for general health was studied. By simultaneous entry of spirituality variables and general health, the direct and indirect effects of each of these variables and finally the mediating role of general health were studied and in each step the research hypotheses were presented and related evidence was presented.

\section{Results}

\section{Research hypotheses}

Hypothesis 1: The components of spirituality predict hope in students.

Second hypothesis: The components of spirituality predict general health in students.

Hypothesis 3: general health components predict students' expectations.

\section{4-3-2- Research question}

Question: Is general health mediating the relationship between the components of spirituality and hope?

Table (2-4): Coefficients of Correlation Between Spirituality

$$
\text { Components and general Health with Hope }
$$

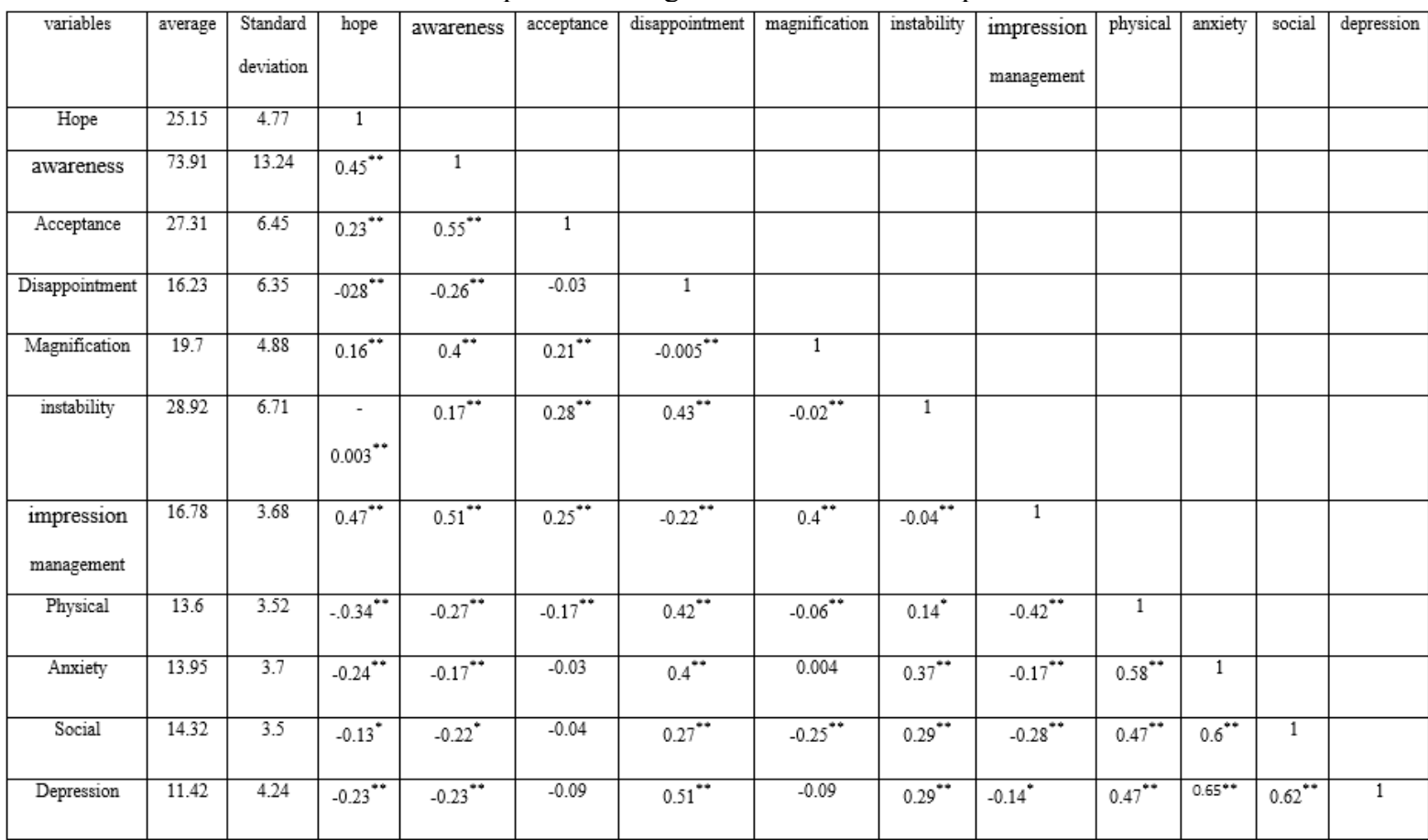

$$
\text { ** } \mathrm{P}<0 / 01 \quad * \mathrm{P}<0 / 05
$$

Table 2-4 shows the Pearson Correlation Coefficients to the components of the variables. The table reports that the relationships between disappointment and physical health $(\mathrm{P}<0.01, \mathrm{r}=0.42)$, anxiety and physical health $(\mathrm{P}<0.01, \mathrm{r}=0.58)$, physical health, and social function Depression and disappointment $(\mathrm{P}<0.01, \mathrm{r}=0.05)$, depression and physical health $(\mathrm{r}=0.47, \mathrm{r}=0.47)$, depression and anxiety $(\mathrm{P}<0.01$ and $\mathrm{r}=0.65)$, and social function and depression $(\mathrm{P}<0.01$ and $\mathrm{r}=0.62)$ were positively significant. These coefficients are further analyzed in the form of regression analysis and path analysis to test the hypotheses and to answer the research question.

Hypothesis 1: The components of spirituality predict hope in students.

Table 3-4 shows prediction of hope based on the components of spirituality. 
Table (3-4): The results of regression analysis to predict factor-based hope based on the components of spirituality.

\begin{tabular}{|c|c|c|c|c|c|}
\hline prediction & beta & t & Sig. & R & $\mathbf{R}^{\mathbf{2}}$ \\
\hline awareness & 0.13 & 1.72 & 0.09 & & \\
\hline Acceptance & 0.04 & 0.65 & 0.52 & \\
Disappointments & -0.13 & -2.01 & 0.04 & \multirow{2}{*}{0.50} & \\
\hline Magnification & 0.06 & 1.07 & 0.28 & \\
\hline instability & -0.11 & -1.80 & 0.07 & \\
\hline impression management & 0.31 & 4.97 & 0.001 & & \\
\hline
\end{tabular}

Based on the results of regression analysis, disappointment component $(\beta=0 / 13 p<0 / 05)$ negatively and impression management $(\beta=0 / 31, p<0 / 01)$ positively predicted factor hopes. The components of spirituality explaining 25 percent of the variance of hope was a factor.

Table 4-4 shows prediction of strategic hope based on the components of spirituality.

Table 4-4: The results of regression analysis to predict strategic hope based on the components of spirituality

\begin{tabular}{|c|c|c|c|c|c|}
\hline prediction & beta & $\mathbf{t}$ & Sig. & $\mathbf{R}$ & $\mathbf{R}^{\mathbf{2}}$ \\
\hline awareness & 0.36 & 5.15 & 0.001 & & \\
Acceptance & -0.02 & -0.28 & 0.78 & & \multirow{2}{*}{0.33} \\
\hline Disappointments & -0.13 & -2.27 & 0.02 & \\
Magnification & -0.20 & -3.59 & 0.001 & & \\
\hline instability & 0.12 & 2.09 & 0.04 & & \\
\hline impression management & 0.30 & 5.13 & 0.001 & & \\
\hline
\end{tabular}

Based on the results of regression analysis, the components of awareness $\beta=0 / 36 p<0 / 01$ ) instability $(\mathrm{P}<0.05, \beta=12)$ and impression management $(\mathrm{p}<0.01$ and $\beta=0 / 30)$ were positive and disappointment $(\beta=-013$, $\mathrm{P}<0.5)$ and magnification $(\beta=-0.20, \mathrm{P}<0.01)$ negatively predicted strategic hope. The components of spirituality explaining $33 \%$ of the variance of strategic hope.

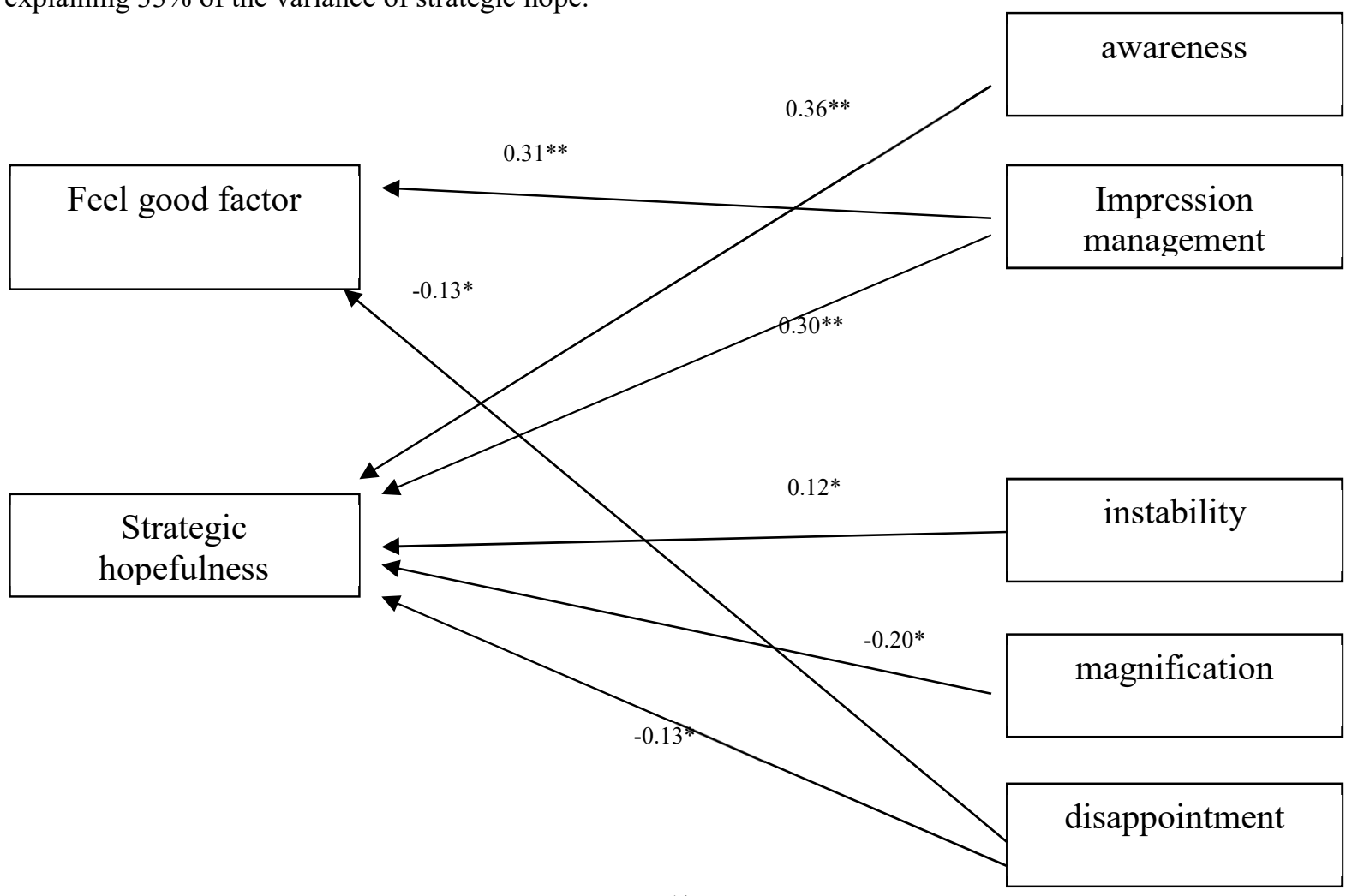

Figure (1-4): Predicting the Components of Hope Based on the Components of Spirituality. Based on the results, the components of management of withdrawal and hopelessness predicted both types of hope. The components of awareness, instability, and magnitude of strategic hope predicted.

Hypothesis 2: The components of spirituality predict general health in students Table 5-4 shows the prediction of depression based on the components of spirituality. 
Table (4-5): The results of regression analysis to predict depression based on spirituality components

\begin{tabular}{|c|c|c|c|c|c|}
\hline prediction & beta & $\mathbf{t}$ & Sig. & $\mathbf{R}$ & $\mathbf{R}^{2}$ \\
\hline awareness & -0.13 & -1.78 & 0.08 & \multirow{6}{*}{0.54} & \multirow{6}{*}{0.29} \\
\hline Acceptance & -0.04 & -0.69 & 0.49 & & \\
\hline Disappointments & 0.43 & 7.06 & 0.001 & & \\
\hline Magnification & -0.04 & -0.62 & 0.54 & & \\
\hline instability & 0.13 & 2.23 & 0.03 & & \\
\hline impression management & 0.04 & 0.66 & 0.51 & & \\
\hline
\end{tabular}

Based on the results of regression analysis, despair $(\beta=0 / 43, p<0.001$ and instability $(\beta=0 / 13, p<0 / 05)$ components predicted the depression component positively. The components of spirituality explained $29 \%$ of variance of depression.

Table 6-4 shows anxiety prediction based on the components of spirituality.

Table 4-6: Results of regression analysis to predict anxiety based on spirituality components

\begin{tabular}{|c|c|c|c|c|c|}
\hline prediction & beta & $\mathbf{t}$ & Sig. & $\mathbf{R}$ & $\mathbf{R}^{2}$ \\
\hline awareness & -0.17 & -2.23 & 0.03 & \multirow{6}{*}{0.51} & \multirow{6}{*}{0.25} \\
\hline Acceptance & -0.03 & -0.41 & 0.68 & & \\
\hline Disappointments & 0.20 & 3.23 & 0.001 & & \\
\hline Magnification & 0.12 & 1.97 & 0.05 & & \\
\hline instability & 0.32 & 5.19 & 0.001 & & \\
\hline impression management & -0.08 & -1.35 & 0.18 & & \\
\hline
\end{tabular}

Based on the results of regression analysis, awareness components $(\beta=0 / 17, \mathrm{p}<0 / 05)$ negatively, and disappointment $(\beta=0 / 20 \mathrm{p}<0 / 001$ and instability components $(\beta=0 / 32 \mathrm{p}<0 / 001$ positively predicted the anxiety component. The components of spirituality explained $25 \%$ of the variance of anxiety. Table 4-7 shows prediction of physical symptoms based on the components of spirituality.

Table 4-7: Results of regression analysis to predict physical symptoms based on spirituality components

\begin{tabular}{|c|c|c|c|c|c|}
\hline prediction & beta & $\mathbf{T}$ & Sig. & $\mathbf{R}$ & $\mathbf{R}^{2}$ \\
\hline awareness & 0.02 & 0.26 & 0.80 & \multirow{6}{*}{0.55} & \multirow{6}{*}{0.30} \\
\hline Acceptance & -0.11 & -1.73 & 0.09 & & \\
\hline Disappointments & 0.33 & 5.41 & 0.001 & & \\
\hline Magnification & 0.10 & 1.77 & 0.08 & & \\
\hline instability & 0.02 & 0.41 & 0.68 & & \\
\hline impression management & -0.37 & -6.26 & 0.001 & & \\
\hline
\end{tabular}

Based on the results of regression analysis, the components of disappointment $(\beta=0 / 33, p<0 / 001$ positively and instability $(\beta=0 / 37, p<0 / 001$ negatively predicted the component of physical symptoms. The components of spirituality explain $30 \%$ of the variance of physical symptoms. Table 8-4 shows the prediction of social function based on the components of spirituality.

Table 8-4: Results of regression analysis to predict social performance based on spirituality components

\begin{tabular}{|c|c|c|c|c|c|}
\hline prediction & beta & $\mathbf{T}$ & Sig. & $\mathbf{R}$ & $\mathbf{R}^{2}$ \\
\hline awareness & -0.12 & -1.52 & 0.13 & \multirow{6}{*}{0.45} & \multirow{6}{*}{0.20} \\
\hline Acceptance & 0.02 & 0.32 & 0.75 & & \\
\hline Disappointments & 0.10 & 1.54 & 0.13 & & \\
\hline Magnification & -0.14 & -2.32 & 0.02 & & \\
\hline instability & 0.26 & 4.06 & 0.002 & & \\
\hline impression management & 0.14 & -2.23 & 0.03 & & \\
\hline
\end{tabular}

Based on regression analysis results, magnification components $(\beta=0 / 14 p<0 / 05)$ negatively and instability components $(\beta=0 / 26 \mathrm{p}<0 / 01)$ positively predicted the social performance component. The 
components of spirituality explain $20 \%$ of the variance of social function.

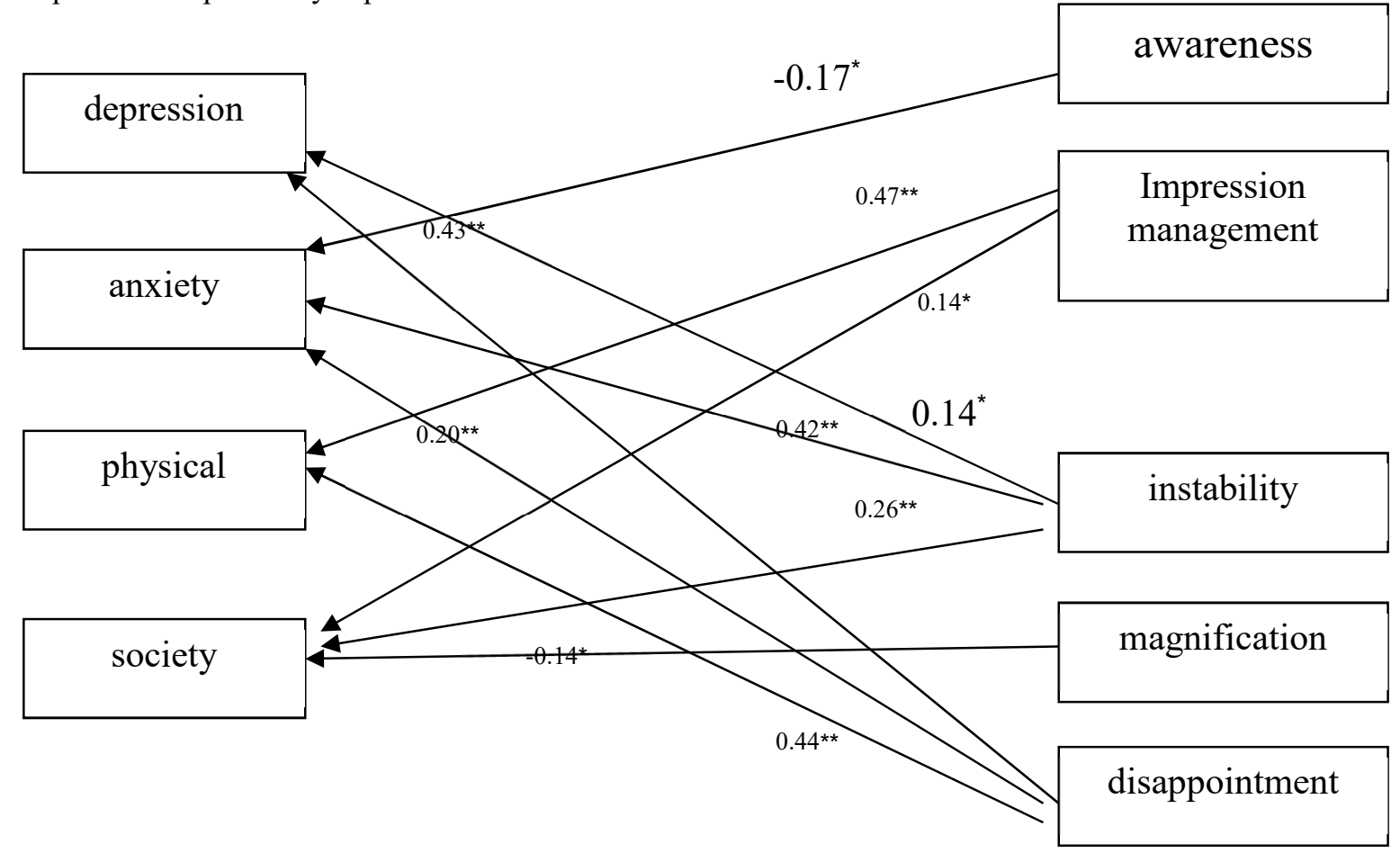

Figure 4-2: Prediction of general health components based on spirituality components

Hypothesis 3: general health components predict students' expectations.

Table 4-4 shows hope expectations based on the components of general health.

Table (4-9): The results of regression analysis to predict factor expectations based on general health components

\begin{tabular}{|c|c|c|c|c|c|}
\hline prediction & beta & T & Sig. & R & $\mathbf{R}^{\mathbf{2}}$ \\
\hline depression & -0.18 & -2.31 & 0.02 & & \multirow{2}{*}{0} \\
\cline { 1 - 4 } anxiety & -0.05 & -0.57 & 0.57 & 0.14 \\
\hline Physical function & -0.27 & -3.92 & 0.001 & & \\
\hline Social function & -0.07 & -0.87 & 0.29 & & \\
\hline
\end{tabular}

$(\beta=0 / 27, \mathrm{p}<0 / 01)$ negatively predicted factor hopes. The components of general health explaining $14 \%$ of the variance of hope was a factor.

Table 4-10 shows the strategic expectation based on the components of general health.

Table (4-10): The results of regression analysis to predict strategic hope based on general health components

\begin{tabular}{|c|c|c|c|c|c|}
\hline prediction & beta & T & Sig. & R & $\mathbf{R}^{\mathbf{2}}$ \\
\hline depression & -0.09 & -1.08 & 0.28 & & \\
anxiety & -0.07 & -0.80 & 0.42 & \multirow{2}{*}{0.32} & 0.10 \\
\hline Physical function & -0.30 & -4.30 & 0.001 & & \\
\hline Social function & 0.20 & 2.68 & 0.009 & & \\
\hline
\end{tabular}

Based on the results of regression analysis, components of physical performance $(\beta=0 / 30 p<0 / 01)$ negatively and social function $(\beta=0 / 20 \mathrm{p}<0 / 01)$ positively predicted strategic hope. The components of general health explain $10 \%$ of the strategic health hope variance. 


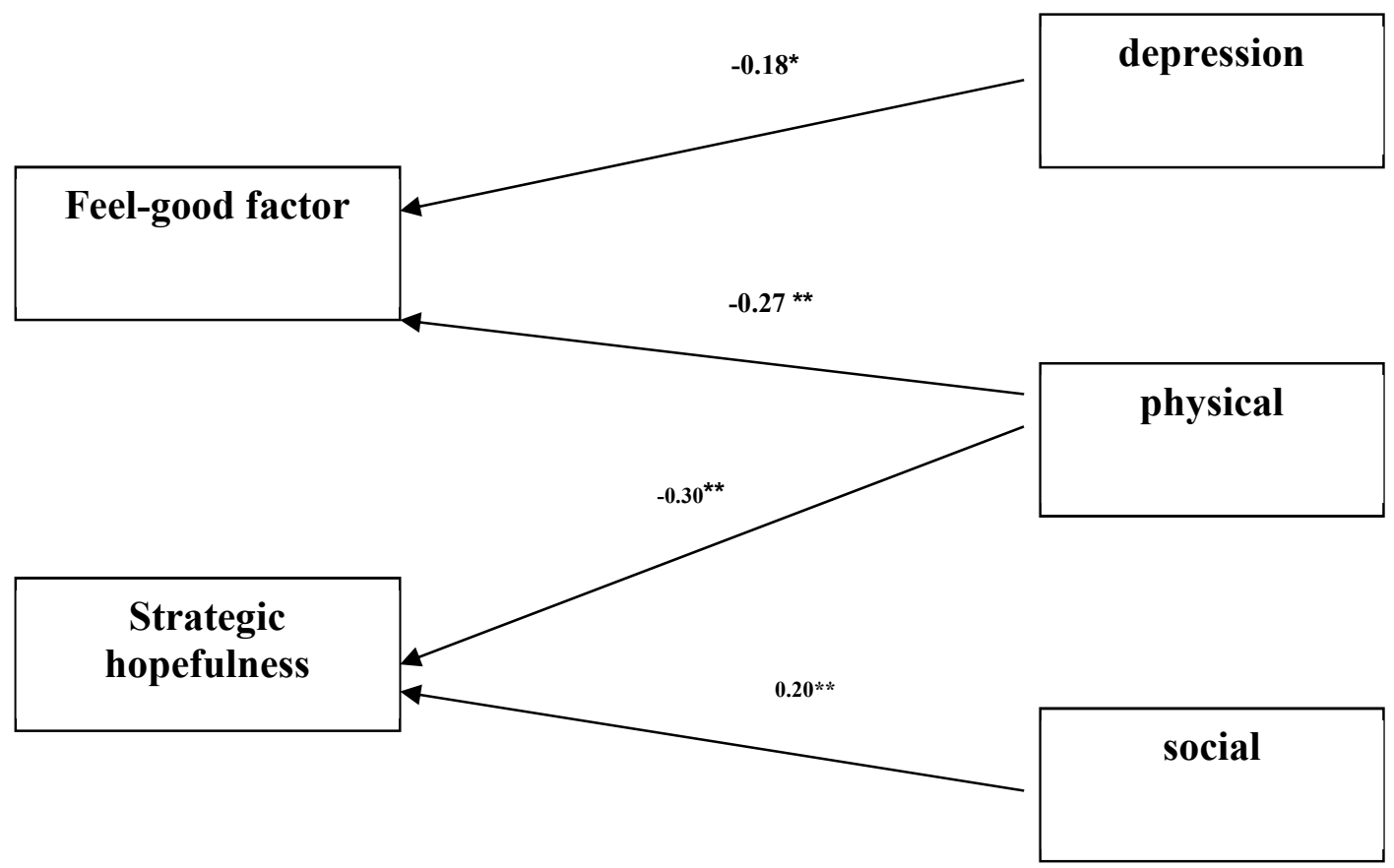

Figure 4-3: Prediction of hope components based on general health components Question: Is general health mediates the relationship between the components of spirituality and hope? Table 4-11 shows the hope of the factor based on the components of spirituality and general health. Table (4-11): The results of regression analysis to predict factor-based hope based on the components of spirituality and general health

\begin{tabular}{|c|c|c|c|c|c|}
\hline prediction & beta & T & Sig. & R & $\mathbf{R}^{\mathbf{2}}$ \\
\hline awareness & 0.11 & 1.54 & 0.13 & \\
\hline Acceptance & 0.01 & 0.22 & 0.83 & \\
\hline Disappointments & -0.007 & -0.09 & 0.93 & \\
\hline Magnification & 0.12 & 1.76 & 0.08 & \multirow{2}{*}{0.54} & \\
\hline instability & -0.12 & -1.63 & 0.11 & \\
\hline impression management & 0.29 & 4.39 & 0.001 & \\
\hline Depression & -0.19 & -2.38 & 0.02 & \\
\hline Anxiety & -0.08 & -1.06 & 0.29 & \\
\hline Physical performance & -0.12 & -1.73 & 0.09 & \\
\hline Social performance & 0.19 & 2.54 & 0.01 & \\
\end{tabular}

Based on the results of regression analysis, the component of management of spiritual self-perception $(\beta=0 / 29, p<0 / 01)$ positively, and depression $(\beta=0 / 19 \mathrm{p}<0 / 05)$ negatively and social function of general health $(\beta=0 / 19 \mathrm{p}<0 / 01)$ positively predicted factor expectations. The components of spirituality and general health explained $29 \%$ of the variance of factor hope. 


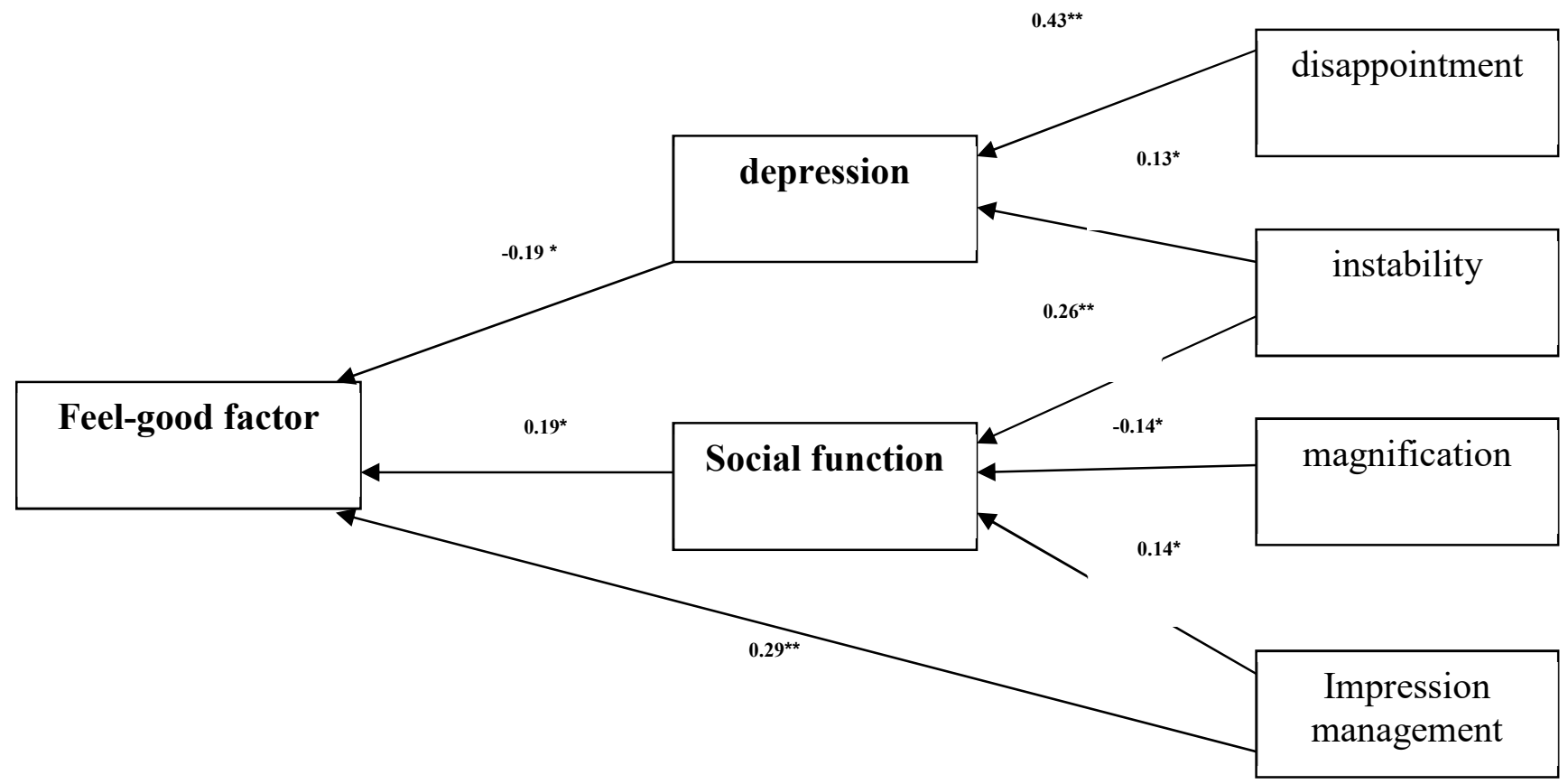

Figure 4-4: Predicting factor hope based on the components of spirituality and mediation

Based on the results of the analysis of the pathway of depression, a complete intermediary is between despair and hopefulness. Based on the results of the pathway analysis, social performance is a relative intermediation between management and hopefulness.

Table 4-12 shows the prediction of strategic hope based on the components of spirituality and general health Table (4-12): The results of regression analysis to predict strategic hope based on the components of spirituality and general health

\begin{tabular}{|c|c|c|c|c|c|}
\hline prediction & beta & T & Sig. & R & $\mathbf{R}^{\mathbf{2}}$ \\
\hline awareness & 0.36 & 5.15 & 0.001 & & \\
\hline Acceptance & -0.03 & -0.57 & 0.57 & \\
\hline Disappointments & -0.09 & -1.33 & 0.18 & \\
\hline Magnification & -0.15 & -2.63 & 0.009 & \multirow{2}{*}{0.61} & \\
\hline instability & 0.11 & 1.82 & 0.07 & \\
\hline impression management & 0.29 & 4.69 & 0.001 & \\
\hline Depression & -0.05 & -0.60 & 0.55 & \\
\hline Anxiety & -0.12 & -1.55 & 0.12 & \\
\hline Physical performance & -0.08 & -1.10 & 0.27 & \\
\hline
\end{tabular}

Based on the results of regression analysis, the components of awareness $(\beta=0 / 36 p<0 / 01)$ and impression management $(\beta=0 / 29 \mathrm{p}<0 / 01)$ positively, magnification $(\beta=0 / 15 \mathrm{p}<0 / 01)$ negatively, and social function of general health $(\beta=0 / 21 \mathrm{p}<0 / 01)$ positively predicted strategic hope. The components of spirituality and general health explain 36 percent of the variance of strategic hope. 


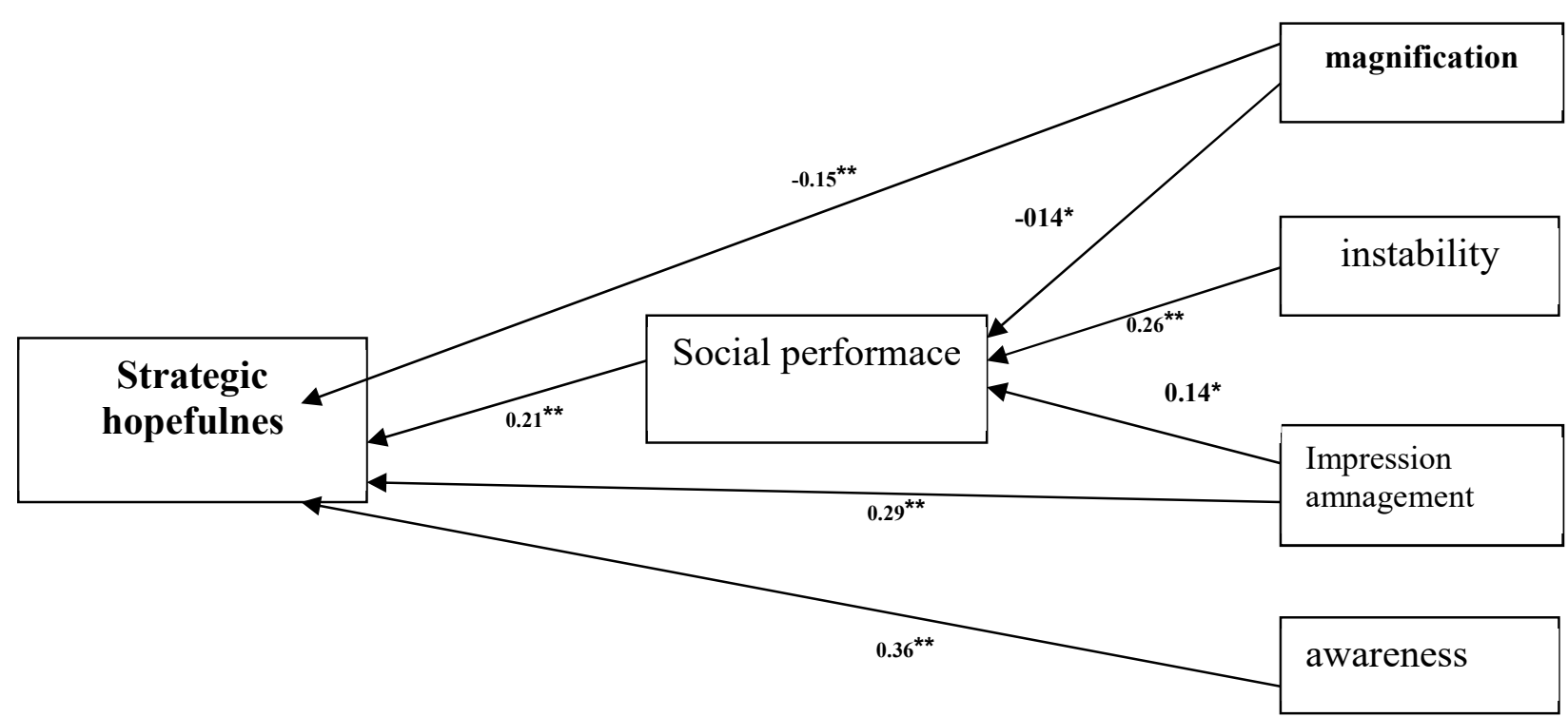

Figure 4-5: Prediction of strategic hope based on the components of spirituality (management of picking and zooming) and mediating the components of general health (social component)

Based on the results of path analysis, social performance is a relative mediation between magnification and strategic hope.

\section{Discussion and conclusion}

Discussion and Conclusion of Findings Related to the Relationship between Spirituality and Hope

The first hypothesis of the research that the components of spirituality predict hope in the students are confirmed for the components of spirituality, disappointment and awareness and management of the perception.

Strategic hope was anticipated by the components of awareness, management, withdrawal, instability, magnification and disappointment.

Knowing how God acts in one's life and knowing that God is leading a person to do things that can lead to strategic hope in people.

The management of the perception depends on the person calling for guidance for each decision he makes. The same desire for guidance from a low-endowed person predicts one's hope.

Instability entails an unsustainable emotional relationship with God. On the other hand, it shows a tendency to withdraw from God, which is the reciprocal predictor of hope.

Feeling the extraordinary ability to change divine providence by worship and that the person believes that God knows that he has more spiritual gain than others. These unrealistic scenarios are negatively predictive of hope.

Despair is described with such reports that there are times when disappointment comes from God or when I feel that I have been rejected by God. These states are inversely related to hope.

Factor hopes were anticipated by management components of withdrawal and hopelessness. Impression management involves a kind of respect and self-esteem for individuals. This is a kind of sense of agency in the individual, which is also a good predictor of individual hope.

Despair represents a kind of disappointment and abandonment from God. These states constitute a state in the individual, which is not coordinated with hope.

This finding was supported by Ebadi, Sudani, Faghihi and Hosseinpour (2009), which showed that positive thinking use with an emphasis on Quranic verses has been effective in increasing the life expectancy of divorced women. The effect of the education is consistent with the results of the follow-up test.

How can this finding be interpreted? The components of spirituality seem to reinforce hope in people through meaningfulness to life and increasing awareness. On the other hand, impression management creates positive feedback from others that excite positive emotions in one person. Emotion-positive excitement provides an appropriate setting for hope in the person.

On the other hand, Schneider's theory is about the process of experiencing hope in a particular situation. In any situation where a purpose is pursued, the purposeful and promising behavior is determined by the interaction of the following:

1. The amount that is given to the return or goal itself.

2. Thinking about possible paths to the goals and expectations that are relevant and how effective they are in reaching the goal.

3- How are the thoughts about personal resources and how one will be effective in tracking the passages to the 
target.

From this conclusion it can be seen that the components of spirituality can be considered as these personal resources. As hoped for therapy, this goal is based on helping patients to formulate clear goals, build multiple paths to reach them, provoke themselves to pursue goals, and set barriers as challenges for overcoming them will re-framerate. These clear goals can be better pursued in the framework of spirituality and spiritual beliefs.

\section{3 Discussion and Conclusion of Findings Related to the Relationship between Spirituality and general Health}

The second hypothesis of the research that the components of spirituality predict general health in students are confirmed for spirituality components including disbelief and instability and management of perception.

The components of anxiety, depression and physical complaints were predicted by disappointment.

Despair represents God's exclusion and abandonment. A rejection of anger in an individual. Such situations are correlated with negative emotions and physical complaints.

The components of anxiety, depression and social function were predicted by instability.

Instability represents an unsustainable emotional relationship with God. A person with this characteristic declares that when he is guilty, he is worried about what God will do with him. Or, when he feels that God does not support him, he feels worthless. This situation is associated with a kind of negative emotion coupled with poor social interactions.

The components of physical complaints and social performance with perceived management were predicted.

Impression management involves a kind of respect and self-esteem for individuals. Such people pray for all friends and relatives every day and are continually ready to worship. These modes improve individual social performance and reduce complaints. Because the respect that a person believes is incompatible with such complaints in interactions.

Social function was predicted by the component of consciousness.

Knowing God is day by day and always with the person. Or equipping the consciousness of God's presence in situations of need. Because, with the support of this awareness, it regulates relations with others on a conscious basis.

Therefore, instability and disappointment with higher components of health and awareness and magnification were shown only with one of the health factors.

These findings are based on the researches of Azhdari Fard, Ghazi and Nooranipour (2010), Gobari Bonab, Motevalli Pour, Hakimi Rad and Habibi (2009), Gholam Ali, Keyvanzadeh and Arjmand (2008), Jafari, Sadri and Fathi Aghdam (2007), Bahrami Dashtaki, Alizadeh, Ghobari Bonab and Karami (2006), and Farahani Nia, Abbasi, Guri and Haqqani (2005).

In interpreting this finding, it can be stated that instability, due to the physiological and psychological changes that it creates, has a clearer relationship with general health. Because these changes affect general health indicators such as anxiety, depression and social function. Anxiety is caused by a perception of a threat that results in physiological reactions, responses that can occur due to instability. Therefore, the relationship between these variables can be explained in the result of the research.

This finding is based on the beliefs of James (according to Pidmont, 2001) that humans find peace and serenity by referring to the origin of religion (spirituality), and believing in the existence of higher values and a superior power for human general health is essential. Hei and Morrissey (1987) believe that the root of spirituality and spiritual experiences is beneficial to human health. Findings associated with the first hypothesis support this usefulness.

\section{4 Discussion and Conclusion of Findings Related to the Relationship between general Health and Hope} The third hypothesis of research suggests that health-promoting components predict hope in students. Both components of hope were predicted by physical complaints. Factor hopes were predicted by depression and strategic hope was predicted by social performance.

Physical complaints include issues such as insomnia and headache, which can reduce the individual's focus. A person with such situations cannot figure out a strategy for achieving goals. This disrupts hoping mechanisms.

Depression consists of negative mood and reduced pleasure. This disturbance in the mood and the reduction of pleasure shorten the future of the person and more involved in the past. Such a mechanism overshadows the agency, therefore, factor expectations are predicted inversely.

Social performance is a good predictor of strategic hope, as it is in an interpersonal context, and provides support and encouragement of the feedback and ideological cycle of others.

This finding coincides with the researches of Alauddini, Kajbaf and Molavi (2007) and the study of Asgari and Ashraf Al-din (2010), which showed a positive relationship between hope and general feeling of well-being. Also, this finding is based on the results of King (1998), Kiani, Pakizeh, Ostoari and Namazi (2010), Hosseinian, Sudani, and Mehrabizadeh Honarmand (2009), Bijari, Ghanbari, Aghamohammadian (2009), Abdi, Taghdisi, 
Naghdi (2009), Asgari and Sharaf al-Din (2008), Shams, Hashemian and Shafi Abadi (2007), and intellectual research, Shafi Abadi, Sanaei Zaker and Harirchi (2007).

In its interpretation, it can be said that physical complaints have shown a relationship with the hope of being tangible. general health is associated with a lack of negative symptoms and is a kind of pleasure in the mind. The same factors provide a person's perspective on the future and a kind of hope that the results suggest is such a situation.

An examination of hope in all aspects of life, including general health, is an essential element. Hope is the ability to believe in a better feeling in the future; and this is the hope that after the crises it will bring peace to the individual. The results of this study showed that general health is a boost to hope. This finding is not contradictory with the statements emphasizing the link between hope and health (Robinson, 1983). This will be twofold in combination with spirituality, a condition that the results of this study confirm.

\subsection{Discussion and Conclusion of Findings Related to the Role of Mediating general Health between Spirituality and Hope}

The research question sought to answer whether general health mediates the relationship between the components of spirituality and hope.

Based on the results, after predicting the variables in the analysis, the prognostic factor by depression was negatively predicted by social function positively. Factor hopes, while predicting these two, were positively predicted by impression management. Social performance was predicted by instability, magnification and management of the perception. Depression was predicted by despair and instability.

Finally, the result was that depression between frustration and hoped-for-life complements mediation, and social performance between management and withdrawal leads to relative interdependence.

The frustration of situations such as disappointment from God, being angry with him, the feeling of rejection from God, and the fact that God has abandoned the individual. All of these situations create a sense of humor and loss of pleasure, that is, the same characteristics of depression. And these negative and unhealthy mood situations lead to disappointment and hopelessness. The negative emotions of crystallization in depression are related to the kind of worthlessness that overwhelms the agency, which can be the main reason for the reduction of hopefulness. In fact, the contribution of the explained variance of hope is one of the negative emotions of depression. These negative emotions arise from the components of spirituality. Therefore, mediation of depression has completely occurred.

The impression management describes with these characteristics that a person calls for guidance from God for any decision he or she takes. He is as kind at home as he is in the mosque. When he goes to the mosque, he is in a state of respect. Days pray for all my friends and relatives. Always ready to worship. These characteristics cover the incidence range beyond the GHQ's social performance. Therefore, in path analysis, part of its explicit variance decreased with the entry of social function. This reduced amount in explaining factor hope is in fact the common inclusion of social performance and impression management. Therefore, the social function intermediation has been partially implemented.

Awareness, magnification and management of perception among spiritual components directly predicted strategic hope. Social performance among general health components predicts strategic hope. Social performance was predicted by magnification, management, and instability.

Ultimately, the result was that social performance between the magnification and the strategic hope of mediation is relative.

The magnification includes the following: the great ability of a person to change divine providence through worship, the awareness of God that the person is more spiritual than most people, the awareness of God that the needs of the individual are more important than the needs of most people, An extraordinary connection that most people do not understand, belief in resorting to God as the best way to obtain whatever one wants, is that one's worship is more effective than God's worship and believes in more talent To most people in the diagnosis of divine providence.

It seems that the part of the actual social function of the individual that modifies or neutralizes these feelings with magnification, then entering the path analysis absorbs parts of the direct relationship of magnification and hope, and keeps the less false and magnified parts. Perhaps the remaining areas of magnification are beyond social function and cannot be absorbed by general health. Therefore, social function has shown the role of relative mediation.

Social performance with spirituality components is more similar to their sociality. Such sexually transmitted variables in a social and interpersonal context are able to attract a network of social support. A socially supportive textbook, rich in good-looking postcards, places one's life in line with the goals that make hope. An explanation elaborating the results obtained in response to the research question.

Multiculturalism is an essential part of clinical activity. To comment religion and spirituality are an essential part of the client's cultural world, and experts are strongly influenced by the results of research showing a positive 
relationship between religious activities and general health, although such relationships do not prove that Religion does not necessarily lead to general health.

Hope is one of the foundations of positivist psychology. Nurturing hopes for the development of the expressed abilities in positive psychology yields two results:

(A) Fostering personal growth and health; and (b) Preventing human illness from being rooted in personality (Rio, 2009). The findings of this study showed that spirituality and general health are related to hope. Therefore, it can be used to cultivate the hope of its correlates, which is the result of research in this direction. Therefore, considering the place that hope has had as an influential variable, it needs to be considered as an associated variable. The results of this study showed that spirituality reinforces this feature.

\section{Resources}

- Taheripour, Ahmad Reza (2007). Psychology of Religion and Nostalgic World. Tehran: Peykan.

- Ebadi, Neda., Sudani, Mansour, Faghihi, Ali Noghi. And Hosseinpour, Mohammad. (1388). The Effectiveness of Positive Recognition Training with Emphasis on Quranic Verses on Increasing the LifeExpectancy of Absolute Women in Ahvaz City. New Findings in Psychology; 4 (10): 71-84.

- Abdi, Nasrin. Taghdisi, Mohammad Hosein and Naghdi, Siran. (1388). The Effectiveness of Promising Promise Interventions in Cancer Patients in Sanandaj, Iran in 2007. Arminagh Danesh; 14 (55): 13-21.

- Asgari, Parviz, and Sharaf al-Din, Heda. (1389). Relationship between social anxiety, hope and social support with general well-being in students, new findings in psychology. 25-36.

- Alauddini, Zohreh, Kajbaf, Mohammad Bagher, and Molavi, Hossein. (1386). A study on the efficacy of group hope therapy on hope and general health, Quarterly Journal of Psychological Health. 1 (4). 67-76.

- Ghobari Bonab, Baqir., Mutolipour, Abbas, Hakimi Rad, Elham. And Habibi Asgharabadi, Mojtaba. (1388). Relationship between Anxiety and Depression with Spirituality in Tehran University Students, Applied Psychology; 3 (2 (10)): 110-123.

- Gholam Ali Lavasani, Masoud, Keyvan Zadeh, Mohammad. And glad, Neda. (1387). Spirituality, Job Stress, Organizational Commitment and Job Satisfaction in Tehran's Nurses, Contemporary Psychology; 3 (2 (6)): 61-73.

- Farahani, thanksgiving. Abbasi, Mozhgan Ghiyori, Azam. And Haqqani, Hamid. (1384). The spiritual health of nursing students and their views on spirituality and spiritual care of patients; Iranian Journal of Nursing, Winter; 18 (44): 7-14.

- $\quad$ Dub, L. , Jodoin, M., \& Kairouz, E. (1998). On the cognitive Basis of subjective well - Being Analysis what do individuals Have to say about it?. Canadian Journal of behavioral science, 30 (1), 1-13.

- $\quad$ Elkins, D. N. (1998). Beyond religion: A Personal program for building a spiritual life outside the walls of traditional religion. Wheaton, IL: The Theosophical Publishing house.

- $\quad$ Finchman. F. (2000). Optimism and Family. Philadelphia : TFP.

- Goldberg, D. P; Williams, P. (1998). The user's guide to the general health questionnaire. NFER-Nelson: Windsor

- Hall, T. W; Edwards, K. J. (2002). The Spiritual Assessment Inventory: A theistic model and measure for assessing spiritual development. Journal for the Scientific Study of Religion, 41, 2, 341-357.

- Hay, D, morisy, A. (1987). Reports of ecstatic paranormal in Great Britain and the United states: A comparison of trends. Journal for the Scientific Study of Religion, 17 (3),255_68.

- Kashdan. W.C. (2003). The values problem in subjective well - being. American psychologist. 56(1).

- $\quad$-King, U.(1998). Spirituality, in JR Hinnels ed., The new penguin handbook of living religions: London, penguin Books. 667681.

- LeDou. J. (1996). The Emotional Brain: The mysterious underpinnings of emotional life. New York:imon \& Schuster.

- McSherry. W. (2000). Education issues surrounding the teaching of spirituality: Nursing Standandards.14 (42) 40

- $\quad$ Myers. D.G. (2000). the funds, friends, and faith of happy people. American psychologist. 55(1). 56-65.

- Nicholls.V., Nicholls.V.(2002). Taken Seriously: The Somerset Spirituality Project: London, general health Foundation. impression

- $\quad$ Pargament, K. I., Koenig, H.G., Perez,L.M.(2000). The many methods of religious coping: development and initial validation of the RCOPE: Juornal of Clinical psychology, 56(4) 519_543.

- Peterson, C. (2000). The future of optimism. American Psychologist, 55: 44-55.

- Peterson, C., Bolling, S. F., Koenig, E.(2002). Private prayer and optimism in middle_age and older patient awaiting cardiac surgery: Gerontologist, 42(1).70_81.

- Piedmont, R. L. (2001). Spiritual transcendence and the scientific study of spirituality. Journal of 
Rehabilitation, 67, 4-14.

- $\quad$ Robinson, L. (1983). Psychiatric nursing: human experience. New York: Saunders.

- Sadock. B., \& Sadock, V. (2005). Synopsis of Psychiatry. New York: Guilford.

- $\quad$ Scheier, M; Carver, C. \& Bridges, M. (2000). Distinguishing optimism from neuroticism: A re-evaluation of the life orientation test. Journal of social psychology and personality, 67, 1063-78.

- Snyder, C. R. (2000). Positive psychology: The scientific and practical explorations of human strengths. New York, Sage publication Inc.

- $\quad$ Snyder, C. R. \& Lopez, S. J. (2002). Handbook of Positive psychology London: oxford university press

- Spilka. B. (2003). The psychology of religion: An empirical approach. New York: Guilford.

- Taylor, Sh.E. (1999). Health Psychology. Forth Edition, University of california:losAngeles. 